\title{
Does Socioeconomic Status Affect Oral Health? Results from the PERSIAN Cohort Study
}

Farid Najafi

Mohammad Hajizadeh

Moslem Soofi

Yahya Salimi

Ali KAzemi Karyani

Shahin Soltani

Sina Ahmadi

Enayatollah Homaie Rad

Behzad Karami MAtin

Yahya Pasdar

Behrooz Hamzeh

Mehdi Moradi Nazar

Ali Mohammadi

Reza Malekzadeh

Tehran University of Medical Sciences

Hossein Poustchi

Nazgol Motamed-Gorji

Alireza Moslem

Ali Asghar Khaleghi

Mohammad Reza Fatthi 
Javad Aghazadeh-Attari

Ali Ahmadi

Farhad Pourfarzi

Mohammad Hossein Somi

Mehrnoush Sohrab

Alireza Ansari-Moghadam

Farhad Edjtehadi

Ali Esmaeili

Farhad Joukar

Mohammad Hasan Lotfi

Teamur Aghamolaei

…

Saied Eslami

Seyed Hamid Reza Tabatabaee

Nader Saki

Ali Akbar Haghdost

Satar Rezaei ( $\nabla$ satarrezaei@gmail.com )

Kermanshah University of Medical Sciences

Research article

Keywords: Socioeconomic status; Oral health; Concentration Index; Decomposition; Iran; PERSIAN

Posted Date: October 17th, 2019

DOI: https://doi.org/10.21203/rs.2.13064/v2

License: (c) This work is licensed under a Creative Commons Attribution 4.0 International License. Read Full License 


\section{Abstract}

Background: The current study aimed to measure and decomposes socioeconomic-related inequalities in DMFT (decayed, missing, and filled teeth) index among adults in Iran. Methods: The study data was drawn from the adult component of Perspective Epidemiological research studies in IrAN (PERSIAN) from 17 centers in 14 different provinces of Iran. DMFT score was used as a measure of oral health among adults in Iran. The relative and generalized (absolute) concentration index (RC and GC, respectively) was used to quantify and decompose socioeconomic-related inequalities in DMFT among Iranian adults (35 years and older). Results: A total of 128813 adults aged 35 and older, who are enrolled in the Prospective Epidemiological Research Studies in IrAN (PERSIAN), were included in the study. The mean score of DMFT of the adults was $6.01(S D=3.17)$. The findings suggested that DMFT was mainly concentrated among the poor in the 14 provinces included in the study $(R C=-0.064 ; 95 \%$ confidence interval $(\mathrm{Cl}),-0.066$ to -0.063 and $\mathrm{GC}=$ $-0.387 ; 95 \% \mathrm{Cl}, 0.397$ to -0.377$)$. In addition, SES, being male, older age and being widow or divorced were identified as the main factors contributing to the concentration of DMFT among the worse-off in Iran. Conclusions: It is recommended to focus in the oral health status of socioeconomically disadvantaged groups in order to reduce socioeconomic-related inequality in oral health among adults in Iran. Moreover, it should be noted that reducing socioeconomic-related inequalities in oral health should be accompanied by appropriate health promotion policies that focus actions on the fundamental socio-economical causes of dental disease.

\section{Introduction}

Oral health is considered an important component of overall health and poor oral health condition adversely affects quality of life of peoples. Poor oral health condition can potentially lead to social and psychological problems. Beside the negative health consequences, poor oral health condition, high prevalence of oral disorders imposes substantial financial burden to individuals, their families, as well as to the society as a whole $(1,2)$. Several indicators have been used in the literature to examine the oral health condition. One of the widely used indices in oral epidemiology literature is DMFT (decayed, missing, and filled teeth) index. As a general indicator of dental health status, the DMFT index is defined as the total number of teeth that are decayed, missed and filled in an individual $(3,4)$. The DMFT index can be used to assess and monitor the oral health status of a given community (5).

Socioeconomic-related inequalities in various health outcomes constitute a main challenge for public health $(4,6,7)$. According to the World Health Organization's Commission on Social Determinants of Health (CSDH), health inequalities are the result of the exposure to health risks among those living in socioeconomically disadvantaged circumstances(8, 9). Previous studies highlighted the significant positive association between socioeconomic status (SES) and oral health status $(10,11)$. The existing literature (10-14) indicated widespread inequalities in oral health outcomes across socioeconomic groups both in developed and developing countries. Higher SES also positively associated with cleaning the teeth more effectively and frequently and with using more oral hygiene aids(15).

Although the prevalence of oral disorders in developed countries has declined significantly in recent years $(12,16-19)$, it remains a major public health concern in developing countries such as Iran. A study by Andrade et al. indicated that a significant socioeconomic inequality related to the negative impact of oral health-related quality of life in Brazil (20). A recent study by Moradi and collogues(4) investigated oral health of people aged 15-40 years in Kurdistan city, western Iran, in 2015 and found significant differences in DMFT index across SES groups. The authors indicated poor DMFT index was more prevalent among disadvantaged people in Kurdistan city. In a systematic review and meta-analysis study indicated that higher tooth loss is associated with the lower income (21). Although the latter study shed some light on the role of SES on oral health status among younger Iranian adults, further research is required to understand socioeconomic-related inequalities in oral health status among adults in different regions in different provinces in Iran. Using information available in the PERSIAN, we aimed to measure socioeconomic inequalities in DMFT index among 
adults (35 years and older) in 14 provinces in Iran. Further, we decomposed socioeconomic inequality in DMFT index in order to identify factors explaining socioeconomic inequality in oral health status in Iran. The results of our study provide useful information for health care policy makers in Iran as a developing country and are useful for other developing regions in order to design effectiveness interventions to decline inequality in oral disorders among Iranian adults.

\section{Methods And Materials}

\section{Study setting}

The study setting was 14 provinces from total 31 provinces of Iran. As a lower-middle-income country, Iran is located in the Eastern Mediterranean Region with an area of 1,648,000 km sq. Based on the 2016 census data, total population of Iran was about 80 million people, with 52 percent living in the 14 provinces included in the study.

\section{Data source and variables}

We used data from the adult component of the PERSIAN, which has been launched by the Ministry of Health and Medical Education (MoHME) to collect epidemiological data from 18 centers in 15 different provinces of Iran: Kermanshah (KSH), Guilan (GU), Fars (FA), East Azerbaijan (EA), Mazandaran (MA), Sistan and Balouchestan (SB), Yazd (YA), Kerman (KE), Khouzestan (KH), Chaharmahal and Bakhtiari (CB), Hormozgan (HO), West Azerbaijan (WA), Ardabil (AR), Razavi Khorasan (RK), and Kohgiluyeh and Boyer-Ahmad (KBA). While there is only one PERSIAN cohort center in each 13 provinces, FA and RK have three and (Fasa, Kavar and Kharameh) two centers (Sabzevar and Mashhad), respectively. We obtained data from all the centers. The characteristics of cohort centers used in the study showed in Appendix 1 . The period time between cohort sites is different and it was varied between 2014 and 2017.

We merged data from the provinces with more than on study centres when we analyzed the data. In addition, data from KBA province excluded from the analysis due to incomplete data collection. Figure 1 presents the flow chart of total samples included in the study.

The participants of the PERSIAN cohorts were invited to the study sites for data collection. The inclusion and exclusion criteria were as follow: the individuals aged 35 years and above whom living at the PERSIAN Cohort sites were in the study. In the small area, all people in the studies age range were included in the study. In the large cities with more than 1 ethnicity, areas known to have better representation of the ethnic groups in mind were chosen. Being of Iranian descent and living in one of the designated areas for at least 9 months of the year included in the study as well as individuals with physical or psychological disabilities that unable to complete the enrollment process are excluded from the study (22).

The cohort questionnaire consists of three parts of general, medical and nutrition with 482 questions. The first part included general questions on demographic, SES, lifestyle, occupational history, physical activity, sleep and circadian rhythm and mobile use. The second part consists of questions related to medical issues (past and present medical history, type of treatment, blood pressure and pulse measurements and oral health). The third part asks questions regarding personal habits questions such as smoking, drinking alcohol and drug use. The cohort questionnaire is administrated by trained interviewers. Quality assurance (QA) and quality control (QC) measures were re-checked by the central and local QA/QC teams to ensure all procedures are performed in accordance with the PERSIAN Cohort protocol. More details about the PERSIAN study can be found elsewhere $(22,23)$.

DMFT score was used as a measure of oral health among adults in Iran. Based on previous studies $(3,4)$, the DMFT score was measured as total number of teeth that are decayed (D), missed (M) and filled (F) in an individual. As per current literature $(4,12,24-26)$, we used a wide variety of demographic (e.g., age groups, sex and marital status), 
unhealthy behaviors (e.g., alcohol drinking and smoking status), SES (e.g., level of education, durable assets, and housing characteristics) and place of residence (cohort site) as determinants of DMFT in the decomposition analysis.

\section{Statistical analysis}

Principal component analysis (PCA) technique $(27,28)$ was used to construct SES of samples. We entered those assets and housing characteristics (e.g., having car, motorcycle, bicycle, refrigerator, freezer, radio, stove, vacuum machine, personal computer, CD/DVD player, sewing machine, cooler, washing mashing, microwave, central heating, having kitchen, bathroom, use of natural gas for cooking, per capita house area per capita rooms and access to piped drinking water, electricity, telephone, internet and sewage network) and education level in the PCA. Based on the socioeconomic scores, samples were divided into five SES groups (quintiles), from poorest to richest.

Thus, we used both relative and generalized (absolute) concentration index (RC and GC, respectively) to quantify and decompose socioeconomic-related inequalities in DMFT among Iranian adults (35 years and older) in the 14 provinces combined as well as in each province, separately. The RC is calculated based on the concentration curve, which graphs the cumulative percentage of participants ranked by SES on the x-axis and the cumulative percentage of a health variable of interest (DMFT score) on the $y$-axis. The RC is equivalent to twice the area between line of perfect equality (45degree line) and concentration curve. The values of the RC ranges from -1 to +1 . If the concentration curve lies under (above) the line of perfect equality, the sign of the RC is positive (negative). The negative value of the RC indicated that DMFT score is more concentrated among rich vice versa. The value of zero suggested perfect equality (29).

(see Formulas in Supplementary Files)

\section{Results}

\section{Descriptive statistics}

The descriptive statistics of all the variables used in the study are presented in Table 1. Of the total of 128813 adults aged 35 and older included in the study, $45.5 \%$ males and $55.5 \%$ females. The average age of participants was 49.3 years (standard deviation SD $=9.18$ ). A majority of the study population $(90.9 \%)$ was married. In addition, about $21.7 \%$ of the samples were smokers and $9.1 \%$ used alcohol in the past year.

The mean (SD) score of D, M, F and DMFT of the adults was 3.30 (4.56), 12.65 (10.45), 2.08 (3.45) and 6.01 (3.17), respectively. There is, however, variation among the provinces in the average score of DMFT score. As illustrated in Fig. 2, the average DMFT score was greater in cohort of Yazd, Fars, East Azerbaijan and Ardabil compared to the rest of cohorts included in the study.

\section{Socioeconomic inequality in DMF}

Figure 3 shows the estimated values of the RC and GC for DMF for the total sample and for each province separately. The findings suggested that DMFT was mainly concentrated among disadvantaged population in the 14 provinces included in the study $(\mathrm{RC}=-0.064 ; 95 \%$ confidence interval $(\mathrm{Cl}),-0.066$ to -0.063 and $\mathrm{GC}=-0.387 ; 95 \% \mathrm{Cl}, 0.397$ to -0.377 ). The estimated RC and GC suggested statistically significant inequality in the DMF in favour of the rich in all cohort centers. The extent of socioeconomic-related inequality in DMFT was found to be especially large in cohort of Kermanshah $(\mathrm{RC}=-0.077$ and $\mathrm{GC}=-0.414)$, Guilan $(\mathrm{RC}=-0.060$ and $\mathrm{GC}=-0.291)$, Fars $(\mathrm{RC}=-0.059$ and $\mathrm{GC}=-0.411)$.

\section{Determinants of socioeconomic inequalities in DMFT}


Table 2 contains the results of the decomposition analysis of socioeconomic-related inequalities in DMFT (RC and GC) measured for all included cohorts. The table reports 1) the coefficients estimating the effect of each explanatory factor on DMFT, 2) the elasticities of DMFT with respect to explanatory variables, 3) the RC for each explanatory variable, and 4) the contribution of each factor to the overall RC and GC for DMFT.

The results of multivariable regression (the coefficients results) indicated that older age was associated with higher DMFT score. Compared to females, males had statistically significantly greater DMFT score. Also, the DMFT score among single was found to be lower than compared to other marital status groups. The mean of DMFT score was lower among people with better-off compared to socioeconomically disadvantaged individuals. Positive associations were found between unhealthily behaviors of smoking status and drinking alcohol and DMFT score. The results also suggested higher DMFT score among individuals residing in the provinces of WA, AR, RK, CB, YA, KE, FA, EA and MA than those living in $\mathrm{KSH}$ province. The DMFT score was found to be lower in the provinces of $\mathrm{GU}, \mathrm{HO}$ and $\mathrm{KH}$ as compared to $\mathrm{KSH}$.

The RC for each of explanatory variables, , were presented in third column of Table 2. A positive value of this index suggested that the explanatory variable is more concentrated among the wealthier people and vice versa. The results indicated those who were male, married, smokers and drinker were relatively wealthier in study population, whereas individuals who were divorced or widowed and older were relatively poor.

The term "contribution" shows that how much the variation of each explanatory variable across SES groups can explain the observed association between SES and DMFT score. If the sign of contribution for a given explanatory factor is positive (negative), it suggests that the socioeconomic distribution of the factor and the association between this variable and DMFT score leads to a higher DMFT score among the better-off (worse-off). Based on the results reported in Table 2, it is evident that that SES is the main factor contributed to the concentration of DMFT score among the poor (70.06\%, calculated as its contribution divided by the total the RC/GC). Besides socioeconomic status, demographic factors (age, gender and divorced or widowed) were the main factors contributed to the concentration of DMFT among lower SES groups in DMFT in the study population.

\section{Discussion}

Poor oral health status is a major public health concern in developed and developing countries. The current studies (1014) also highlighted socioeconomic inequalities in oral health status (defined as differences in incidence or prevalence of oral disorders) across socioeconomic groups. Although inequality in oral health status continues to be a main public health issue in Iran, there exists scant studies that aim to examine socioeconomic inequalities in oral health in Iran(4). Using data collected from 17 PERSIAN cohort centers in 14 provinces, we measured and decomposed socioeconomicrelated inequalities in DMFT among adults in Iran and across different regions in Iran.

The average DMFT index was found to be 6.01 in 14 provinces in Iran with significant variation across provinces. We found statistically significant pro-rich inequality in DMFT score in all the provinces included in the study. Socioeconomicrelated inequality in DMFT score was found to be large in provinces such as Kermanshah, Guilan and Fars. A study by Moradi and collogues also indicated that the higher concentration of poor DMFT score among the poor in Kurdistan city, $\operatorname{Iran}(4)$.

In addition to SES, our study also showed that being female, older adults, married, smoking and drinking alcohol were associated with higher DMFT score among Iranian adults. Our study indicated that higher DMFT score among individuals residing in the cohorts of WA, $A R, R K, C B, Y A, K E, F A, E A$ and MA compared to other provinces included in the study. A study by Piovesan et al.(32) also found higher DMFT scores among women compared to men. A study conducted by Ditmyer et al.(12) also indicated that a higher DMFT scores among women and older individuals. Since 
older adults as total of population in Iran is increasing, this finding calls for further attention to deliver oral health care in this population. Previous work also highlighted unhealthy behavior (e.g., drinking alcohol and smoking) as main determinants of oral health $(32,33)$. One possible explanation of the effect of drinking on DMFT score is that alcohol users consume high amount of refined carbohydrates and neglect both personal and professional health care, which, in turn, may lead to high DMFT score among these population. In line with previous studies $(34,35)$, we found that higher DMFT score among smokers than non-smokers.

The decomposition results indicated that SES itself is the main determinant of socioeconomic-related inequality in DMFT score in Iran. The negative effect of SES on DMFT score can be due to, for example, lower access of lower SES individuals to dental health care services compared to their higher SES counterparts. Beside SES, being male and older age and widow or divorced were the main factors contributing to the concentration of DMFT among the worse-off in Iran. The negative contribution of being male to socioeconomic inequality in DMFT is explained by the fact that men compared to women have lower DMFT score (see the negative elasticity reported for this variable in Table 2) and they are relatively better-off compared to women in Iran (see the positive for this variable Table 2). Older age and being window or divorced increase the concentration of DMFT score among the poor because older adults and those who are window or divorced in Iran have higher score of DMTF score (see the positive elasticity reported for these variables in Table 2) and they are relatively poor in Iran (see the negative for these two variables in Table 2).

The findings of the present study should be interpreted in light of some limitations. Firstly, since this study is a crosssectional design, we were unable to establish causal relationships between explanatory variables and DMFT score in the decomposition analysis. Secondly, data for this study extracted from 14 provinces in Iran; thus, the generalizability of our results to other provinces is partially limited.

\section{Conclusion}

This study revealed that poor oral health status, as measured by DMTF score, was concentrated among socioeconomically disadvantaged adults in Iran. We also observed significant variations in socioeconomic inequality in DMTF score among different provinces in Iran. As our study demonstrated SES, being male, older age and being widow or divorced as the main factors contributing to the concentration of DMFT among the worse-off in Iran, it is recommended to focus in the oral health status of these groups in order to reduce socioeconomic inequality in oral health among adults in Iran. For example, as the existing studies (e.g., (36-39)) showed pro-rich inequalities in health care utilization in Iran, it is recommended to expand oral health care services for these groups through publicly funded primary health care in Iran. Moreover, it should be noted that reducing socioeconomic inequalities in oral health should be accompanied by appropriate health promotion policies that focus actions on the fundamental SES causes of dental disease.

\section{Abbreviations}

DMFT: decayed, missing, and filled teeth

SES: socioeconomic status

PERSIAN: Prospective Epidemiologic Research Study in IRaN

MoHME: Ministry of Health and Medical Education

PCA: Principal component analysis

$\mathrm{RC}$ : relative concentration index 
GC: generalized (absolute) concentration index

OLS: ordinary least squares

\section{Declarations}

\section{Ethics approval and consent to participate}

While each cohort center received the ethical approval from local universities, for the purpose of this study and pooling all PERSIAN data, the ethics committee of Kermanshah University of Medical Sciences approved the study (IR.KUMS.REC.1397.187).

\section{Consent for publication}

Not applicable.

Availability of data and material

All necessary data are presented within the manuscript. All other materials and data are available upon request.

\section{Competing Interests}

The authors declare no conflict of interest

\section{Funding}

The Iranian of Ministry Health and Medical Education has contributed to the funding used in the PERSIAN Cohort through Grant no. 700/534.

\section{Authors' contributions}

SR, YS, AKK, ShS, MS, SA, BKM, MMN, FN, MH and HER: contributed with the research idea, study design, performing the study, analyses of data and writing the manuscript. AM: designed the chart and graph; YP, BH, RM, HP, NMG, AAK, MRF, JAA, AA, FP, MHS, MS, AAM, FE, AE, FJ, MHL, TA, SE, SHRT, NS and AAH helped to data collection. All authors approved the final manuscript as submitted and agreed to be accountable for all aspects of the work.

\section{Acknowledgement}

This study could not be completed without the great efforts of the participants, then, we thanks to all of them.

\section{References}

1. Jin L, Lamster I, Greenspan J, Pitts N, Scully C, Warnakulasuriya S. Global burden of oral diseases: emerging concepts, management and interplay with systemic health. Oral diseases. 2016;22(7):609-19.

2. Cohen-Carneiro F, Souza-Santos R, Rebelo MAB. Quality of life related to oral health: contribution from social factors. Ciência \& Saúde Coletiva. 2011;16:1007-15.

3. Organization WH. Oral health surveys: basic methods: World Health Organization; 2013.

4. Moradi G, Moinafshar A, Adabi H, Sharafı M, Mostafavi F, Bolbanabad AM. Socioeconomic Inequalities in the Oral Health of People Aged 15-40 Years in Kurdistan, Iran in 2015: A Cross-sectional Study. Journal of Preventive Medicine and Public Health. 2017;50(5):303. 
5. Marthaler T. Changes in dental caries 1953-2003. Caries research. 2004;38(3):173-81.

6. Culyer AJ, Wagstaff A. Equity and equality in health and health care. Journal of health economics. 1993;12(4):43157.

7. Pulok MH, Uddin J, Enemark U, Hossin MZ. Socioeconomic inequality in maternal healthcare: An analysis of regional variation in Bangladesh. Health \& place. 2018;52:205-14.

8. Scholes S, Bajekal M, Love H, Hawkins N, Raine R, O'Flaherty M, et al. Persistent socioeconomic inequalities in cardiovascular risk factors in England over 1994-2008: a time-trend analysis of repeated cross-sectional data. BMC public health. 2012;12(1):129.

9. Lago S, Cantarero D, Rivera B, Pascual M, Blázquez-Fernández C, Casal B, et al. Socioeconomic status, health inequalities and non-communicable diseases: a systematic review. Journal of Public Health. 2018;26(1):1-14.

10. Turrell G, Sanders AE, Slade GD, Spencer AJ, Marcenes W. The independent contribution of neighborhood disadvantage and individual-level socioeconomic position to self-reported oral health: a multilevel analysis. Community dentistry and oral epidemiology. 2007;35(3):195-206.

11. Elani H, Harper S, Allison P, Bedos C, Kaufman J. Socio-economic inequalities and oral health in Canada and the United States. Journal of dental research. 2012;91(9):865-70.

12. Ditmyer M, Dounis G, Mobley C, Schwarz E. Inequalities of caries experience in Nevada youth expressed by DMFT index vs. Significant Caries Index (SiC) over time. BMC oral health. 2011;11(1):12.

13. Roland E, Gueguen G, Longis M, Boiselle J. Validation of the reproducibility of the DMF Index used in bucco-dental epidemiology and evaluation of its 2 clinical forms. World health statistics quarterly Rapport trimestriel de statistiques sanitaires mondiales. 1994;47(2):44-61.

14. Tsakos G, Demakakos P, Breeze E, Watt RG. Social gradients in oral health in older adults: findings from the English longitudinal survey of aging. American journal of public health. 2011;101(10):1892-9.

15. Watt R, Sheiham A. Inequalities in oral health: a review of the evidence and recommendations for action. British dental journal. 1999;187(1).

16. Petersen PE, Bourgeois D, Ogawa H, Estupinan-Day S, Ndiaye C. The global burden of oral diseases and risks to oral health. Bulletin of the World Health Organization. 2005;83:661-9.

17. Dye BA, Tan S, Smith V, Barker LK, Thornton-Evans G, Eke PI, et al. Trends in oral health status; United States, 19881994 and 1999-2004. 2007.

18. Ghorbani Z, Ahmady AE, Ghasemi E, Zwi A. Socioeconomic inequalities in oral health among adults in Tehran, Iran. Community Dent Health. 2015;32(1):26-31.

19. Ghorbani Z, Peres KG. Is the association between socioeconomic status and nonreplaced extracted teeth mediated by dental care behaviours in adults? Community dentistry and oral epidemiology. 2015;43(6):532-9.

20. Bof de Andrade F, Drumond Andrade FC. Socioeconomic Inequalities in Oral Health-Related Quality of Life among Brazilians: A Cross-Sectional Study. Dentistry journal. 2019;7(2):39.

21. Seerig LM, Nascimento GG, Peres MA, Horta BL, Demarco FF. Tooth loss in adults and income: Systematic review and meta-analysis. Journal of Dentistry. 2015;43(9):1051-9.

22. Poustchi H, Eghtesad S, Kamangar F, Etemadi A, Keshtkar A-A, Hekmatdoost A, et al. Prospective Epidemiological Research Studies in Iran (the PERSIAN Cohort Study): Rationale, Objectives, and Design. American journal of epidemiology. 2017;187(4):647-55.

23. Eghtesad S, Mohammadi Z, Shayanrad A, Faramarzi E, Joukar F, Hamzeh B, et al. The PERSIAN cohort: Providing the evidence needed for healthcare reform. Archives of Iranian medicine. 2017:291-5.

24. Ha DH, Xiangqun J, Cecilia MG, Jason A, Do LG, Jamieson LM. Social inequality in dental caries and changes over time among Indigenous and non-Indigenous Australian children. Australian and New Zealand journal of public 
health. 2016;40(6):542-7.

25. Mathur MR, Tsakos G, Millett C, Arora M, Watt R. Socioeconomic inequalities in dental caries and their determinants in adolescents in New Delhi, India. BMJ open. 2014;4(12):e006391.

26. Ghorbani Z, Ahmady AE, Lando HA, Yazdani S, Amiri Z. Development of a socioeconomic status index to interpret inequalities in oral health in developing countries. Oral Health Prev Dent. 2013;11(1):9-15.

27. Vyas S, Kumaranayake L. Constructing socio-economic status indices: how to use principal components analysis. Health policy and planning. 2006;21(6):459-68.

28. Kolenikov S, Angeles G. Socioeconomic status measurement with discrete proxy variables: Is principal component analysis a reliable answer? Review of Income and Wealth. 2009;55(1):128-65.

29. Wagstaff A, Paci P, Van Doorslaer E. On the measurement of inequalities in health. Social science \& medicine. 1991;33(5):545-57.

30. O'Donnell O, Van Doorslaer E, Wagstaff A, Lindelow M. Analyzing health equity using household survey data: a guide to techniques and their implementation: The World Bank; 2007.

31. Wagstaff A, Doorslaer vE, Watanabe N. On decomposing the causes of health sector inequalities with an application to malnutrition inequalities in Vietnam: The World Bank; 2001.

32. Piovesan C, Mendes FM, Antunes JLF, Ardenghi TM. Inequalities in the distribution of dental caries among 12-yearold Brazilian schoolchildren. Brazilian Oral Research. 2011;25(1):69-75.

33. Dasanayake AP, Warnakulasuriya S, Harris CK, Cooper DJ, Peters TJ, Gelbier S. Tooth decay in alcohol abusers compared to alcohol and drug abusers. International journal of dentistry. 2010;2010.

34. Al-Weheb AM. Smoking and its relation to caries experience and salivary lactobacilli count. Journal of baghdad college of dentistry. 2005;17(1):92-5.

35. Vellappally S, Fiala Z, Šmejkalová J, Jacob V, Shriharsha P. Influence of tobacco use in dental caries development. Central European journal of public health. 2007;15(3).

36. Hajizadeh M, Connelly LB, Butler JR, Khosravi A. Unmet need and met unneed in health care utilisation in Iran. International Journal of Social Economics. 2012;39(6):400-22.

37. Rezaei S, Ghahramani E, Hajizadeh M, Nouri B, Bayazidi S, Khezrnezhad F. Dental care utilization in the west of Iran: a cross-sectional analysis of socioeconomic determinants. International Journal of Human Rights in Healthcare. 2016;9(4):235-41.

38. Rezaei S, Woldemichael A, Zandian H, Homaie Rad E, Veisi N, Karami Matin B. Dental health-care service utilisation and its determinants in West Iran: a cross-sectional study. International dental journal. 2018;68(3):176-82.

39. Rad EH, Kavosi Z, Arefnezhad M. Economic inequalities in dental care utilizations in Iran: Evidence from an urban region. Medical journal of the Islamic Republic of Iran. 2016;30:383.

\section{Tables}

Table 1. Descriptive statistics of variables used in the study 


\begin{tabular}{|c|c|c|}
\hline Variables & Proportion (\%) & $\begin{array}{l}\text { Standard } \\
\text { deviation }\end{array}$ \\
\hline \multicolumn{3}{|l|}{ Age groups } \\
\hline $35-44$ & 35.7 & 47.93 \\
\hline $45-54$ & 33.6 & 47.24 \\
\hline $55-64$ & 24.2 & 42.83 \\
\hline 65 and older & 6.4 & 24.46 \\
\hline \multicolumn{3}{|l|}{ Sex } \\
\hline Male & 44.51 & 49.69 \\
\hline Females & 55.49 & 49.69 \\
\hline \multicolumn{3}{|l|}{ Marital status } \\
\hline Single & 2.27 & 14.90 \\
\hline Married & 90.91 & 28.73 \\
\hline Divorced or widowed & 6.82 & 25.19 \\
\hline \multicolumn{3}{|l|}{ Smoking status } \\
\hline Smoker & 21.68 & 41.21 \\
\hline Non-smoker & 78.32 & 41.21 \\
\hline \multicolumn{3}{|l|}{ Drinking alcohol } \\
\hline Yes & 9.10 & 28.71 \\
\hline No & 90.90 & 28.71 \\
\hline \multicolumn{3}{|l|}{ Socioeconomic status } \\
\hline 1 (Poorest) & 19.87 & 39.90 \\
\hline 2 & 19.94 & 39.97 \\
\hline 3 & 20.04 & 40.03 \\
\hline 4 & 20.09 & 40.04 \\
\hline 5 (Wealthiest) & 20.10 & 40.07 \\
\hline \multicolumn{3}{|l|}{ Region of cohort } \\
\hline Kermanshah (KSH) & 7.79 & 26.80 \\
\hline Guilan (GU) & 8.15 & 27.35 \\
\hline Fars (FA) & 17.28 & 37.75 \\
\hline East Azerbaijan (EA) & 11.59 & 31.96 \\
\hline Mazandaran (MA) & 7.96 & 27.02 \\
\hline Sistan and Balouchestan (SB) & 6.37 & 24.38 \\
\hline Yazd (YA) & 7.20 & 25.84 \\
\hline Kerman (KE) & 7.66 & 26.60 \\
\hline
\end{tabular}




\begin{tabular}{lcc}
\hline Khouzestan (KH) & 6.97 & 25.46 \\
\hline Chaharmahal and Bakhtiari (CB) & 5.16 & 22.11 \\
\hline Hormozgan (HO) & 2.58 & 15.86 \\
\hline West Azerbaijan (WA) & 2.67 & 16.13 \\
\hline Ardabil (AR) & 6.35 & 24.38 \\
\hline Razavi Khorasan (RK) & 2.27 & 14.86 \\
\hline
\end{tabular}

Table 2. Decomposition of socioeconomic inequalities (the RC and GC) in DMTF in Iran 


\section{Absolute Summed Absolute Summed}

\begin{tabular}{|c|c|c|c|c|c|c|c|c|}
\hline $\begin{array}{l}\text { Demographic } \\
\text { variables } \\
\text { Age groups }\end{array}$ & & & & & & & & \\
\hline $35-44$ & ref & & & & & & & \\
\hline $45-54$ & $1.357^{*}$ & 0.076 & 0.028 & 0.002 & & 0.013 & & \\
\hline $55-64$ & $2.857^{*}$ & 0.115 & -0.074 & -0.008 & & -0.051 & & \\
\hline $\begin{array}{l}65 \text { and } \\
\text { older }\end{array}$ & $3.771^{*}$ & 0.040 & -0.216 & -0.009 & & -0.052 & & \\
\hline Sex & & & & & & & & \\
\hline Male & $-0.371^{*}$ & -0.027 & 0.106 & -0.003 & & -0.018 & & \\
\hline Females & ref & & & & & & & \\
\hline Marital status & & & & & & & & \\
\hline Single & ref & & & & & & & \\
\hline Married & $0.548^{*}$ & 0.083 & 0.026 & 0.002 & & 0.013 & & \\
\hline $\begin{array}{l}\text { Divorced or } \\
\text { widowed }\end{array}$ & $0.590^{*}$ & 0.007 & -0.285 & -0.002 & -0.018 & -0.011 & -0.106 & 29.22 \\
\hline $\begin{array}{l}\text { Socioeconomi } \\
\text { status variable }\end{array}$ & & & & & & & & \\
\hline 1 (Poorest) & ref & & & & & & & \\
\hline 2 & $-0.338^{*}$ & -0.011 & -0.403 & 0.005 & & 0.027 & & \\
\hline 3 & $-0.612^{*}$ & -0.020 & -0.003 & 0.000 & & & & \\
\hline 4 & $-0.900^{*}$ & -0.030 & 0.398 & -0.012 & & -0.072 & & \\
\hline $\begin{array}{l}5 \\
\text { (Wealthiest) }\end{array}$ & $-1.311^{*}$ & -0.044 & 0.799 & -0.035 & -0.042 & -0.211 & -0.255 & 70.06 \\
\hline $\begin{array}{l}\text { Behavioral } \\
\text { variables }\end{array}$ & & & & & & & & \\
\hline $\begin{array}{l}\text { Smoking } \\
\text { status }\end{array}$ & & & & & & & & \\
\hline Smoker & $1.360^{*}$ & 0.049 & 0.047 & 0.002 & & 0.014 & & \\
\hline $\begin{array}{l}\text { Non- } \\
\text { smoker }\end{array}$ & ref & & & & & & & \\
\hline $\begin{array}{l}\text { Drinking } \\
\text { alcohol }\end{array}$ & & & & & & & & \\
\hline Yes & $0.134^{*}$ & 0.002 & 0.203 & 0.000 & 0.003 & 0.002 & 0.016 & -4.52 \\
\hline No & ref & & & & & & & \\
\hline $\begin{array}{l}\text { Region } \\
\text { (province) }\end{array}$ & ref & & & & & & & \\
\hline $\begin{array}{l}\text { Kermanshah } \\
\text { (KSH) }\end{array}$ & & & & & & & & \\
\hline Guilan (GU) & $-0.980^{*}$ & -0.013 & -0.209 & 0.003 & & 0.017 & & \\
\hline Fars (FA) & $0.936^{*}$ & 0.027 & -0.334 & -0.009 & & -0.054 & & \\
\hline $\begin{array}{l}\text { East } \\
\text { Azerbaijan } \\
\text { (EA) }\end{array}$ & $1.398^{*}$ & 0.027 & 0.019 & 0.001 & & 0.003 & & \\
\hline $\begin{array}{l}\text { Mazandaran } \\
\text { (MA) }\end{array}$ & $0.200^{*}$ & 0.003 & 0.143 & 0.000 & & 0.002 & & \\
\hline $\begin{array}{l}\quad \text { Sistan and } \\
\text { Balouchestan } \\
\text { (SB) }\end{array}$ & $0.070^{* *}$ & 0.001 & 0.023 & 0.000 & & 0.000 & & \\
\hline Yazd (YA) & $1.267^{*}$ & 0.015 & 0.226 & 0.003 & & 0.021 & & \\
\hline $\begin{array}{l}\text { Kerman } \\
(\mathrm{KE})\end{array}$ & $0.920^{*}$ & 0.012 & 0.313 & 0.004 & & 0.022 & & \\
\hline $\begin{array}{l}\text { Khouzestan } \\
(\mathrm{KH})\end{array}$ & $-1.786^{*}$ & -0.021 & -0.257 & 0.005 & & 0.032 & & \\
\hline
\end{tabular}


Chaharmahal
$0.724^{*}$
0.006
$0.472 \quad 0.003$
0.018

and

Bakhtiari(CB)

(HO)

Hormozgan

West

Azerbaijan

$-1.855^{*}$

$-0.008$

$\begin{array}{ll}-0.148 & 0.001\end{array}$

0.007

(WA)

Ardabil

$0.578^{*}$

0.003

$-0.140 \quad 0.000$

$-0.002$

(AR)

Razavi

$1.195^{*}$

0.013

0.256

0.003

0.019

Khorasan

$0.190^{*} \quad 0.001$

$0.566 \quad 0.000$

0.015

0.002

0.087

$-23.97$

(RK)

Sum

Residual

Total RC/GC

$-0.043$

$-0.018$

$-0.061$

$-0.258$

69.8

$-0.106 \quad 29.20$

$-0.364 \quad 100$

** P-value less than 0.1. *P-value less than 0.001

Note: $r e f=$ reference category in the analysis

\section{Appendix 1}

\section{Appendix 1}

The characteristics of cohort centers in Iran

\begin{tabular}{|c|c|c|c|c|c|c|}
\hline$\overline{\text { Row }}$ & Province & Population* & Cohort site & Population* & Cohort population & Main Ethnicities \\
\hline 1 & Ardabil & $1,270,420$ & Ardabil & 529,374 & 8,192 & Turk \\
\hline 2 & Chaharmahal and Bakhtiari & 947,763 & Sharekord & 93,104 & 6,664 & Lor \\
\hline$\overline{3}$ & East Azerbaijan & $3,909,652$ & Khameneh & 3,056 & 14,978 & Turk, Azari \\
\hline \multirow[t]{3}{*}{$\overline{4}$} & \multirow[t]{3}{*}{ Fars } & \multirow[t]{3}{*}{$4,851,274$} & Kavar & 31,711 & 2,244 & Fars, Turk \\
\hline & & & Kharameh & 18,477 & 10,662 & Fars, Arab \\
\hline & & & Fasa & 110,825 & 10,113 & Fars, Arab and Turk \\
\hline 5 & Guilan & $2,530,696$ & Some'e Sara & 58,658 & 10,511 & Gilaki \\
\hline$\overline{6}$ & Hormozgan & $1,776,415$ & Bandare Kong & 19,213 & 3,570 & Arab \\
\hline 7 & Kerman & $3.164,718$ & Rafsanjan & 161,909 & 9,982 & Fars \\
\hline 8 & Kermanshah & $1,952,434$ & Ravansar & 47,657 & 10,077 & Kurd \\
\hline$\overline{9}$ & Khouzestan & $4,710,506$ & Hoveizeh & 19,481 & 9,156 & Arab \\
\hline$\overline{10}$ & Mazandaran & $3,283,582$ & Sari & 309,820 & 10,253 & Tabari \\
\hline \multirow[t]{2}{*}{11} & \multirow[t]{2}{*}{ Razavi Khorasan } & \multirow[t]{2}{*}{$6,434,501$} & Mashhad & $3,001,184$ & 2,189 & Fars \\
\hline & & & Sabzevar & 243,700 & 784 & Fars \\
\hline$\overline{12}$ & Sistan and Balouchestan & $2,775,014$ & Zahedan & 587,730 & 8,318 & Balouch \\
\hline$\overline{13}$ & West Azerbaijan & $3,265,219$ & Ghoushchi & 2,787 & 3,662 & Turk, Azari \\
\hline$\overline{14}$ & Yazd & $1,138,533$ & Shahedieh, Yazd & 18,309 & 9,901 & Fars \\
\hline
\end{tabular}

References: 1- Persian cohort sites, available from: http://persiancohort.com/cohortsites/, access: April 21, 2019. 2- Iran statistics center, available from: https://www.amar.org.ir, access: April 21, 2019.

\section{Figures}




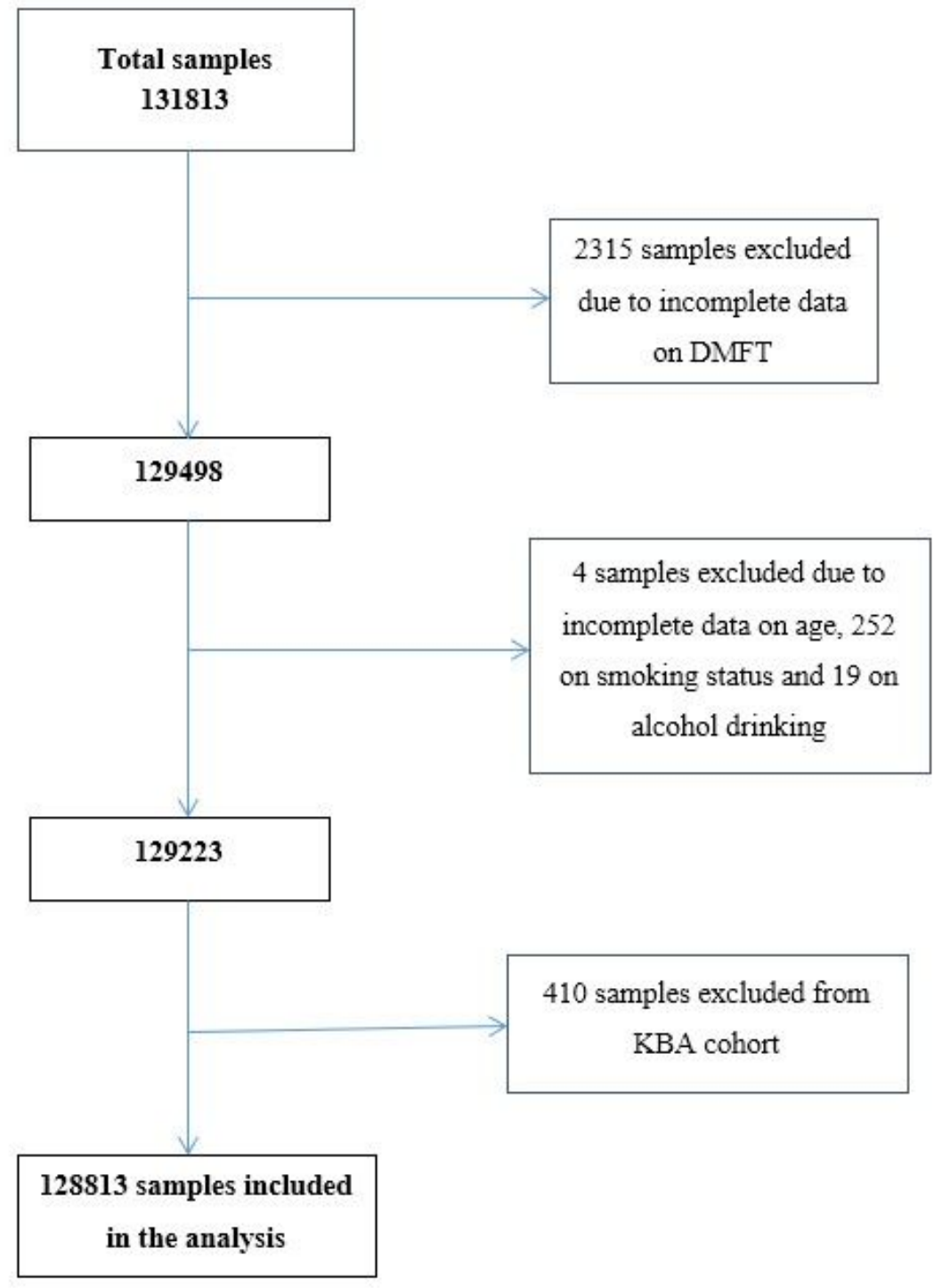

Figure 1

Flow chart of samples included in the analysis 


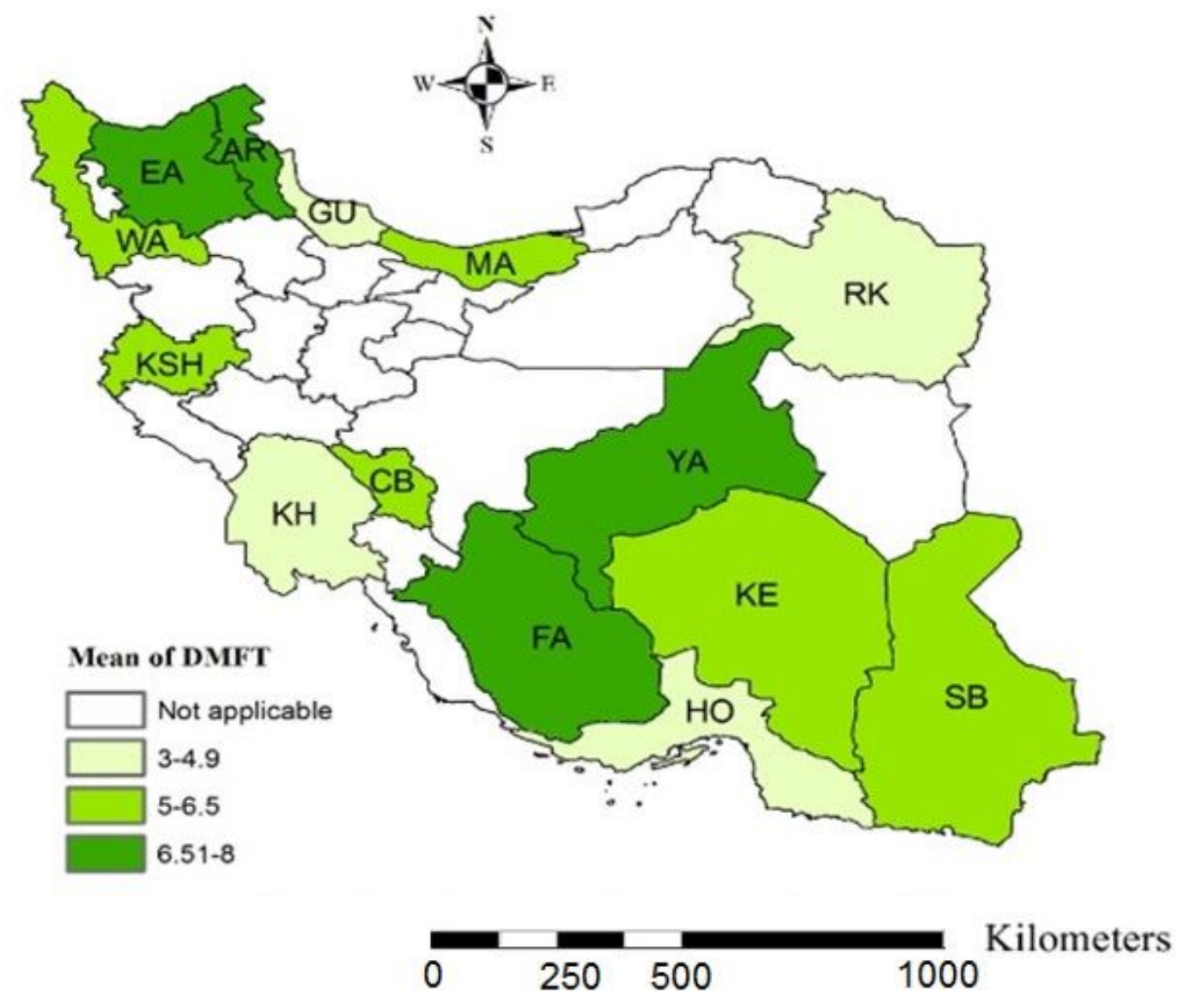

Figure 2

Mean of DMFT score as an indicator for oral health across 14 provinces in Iran 

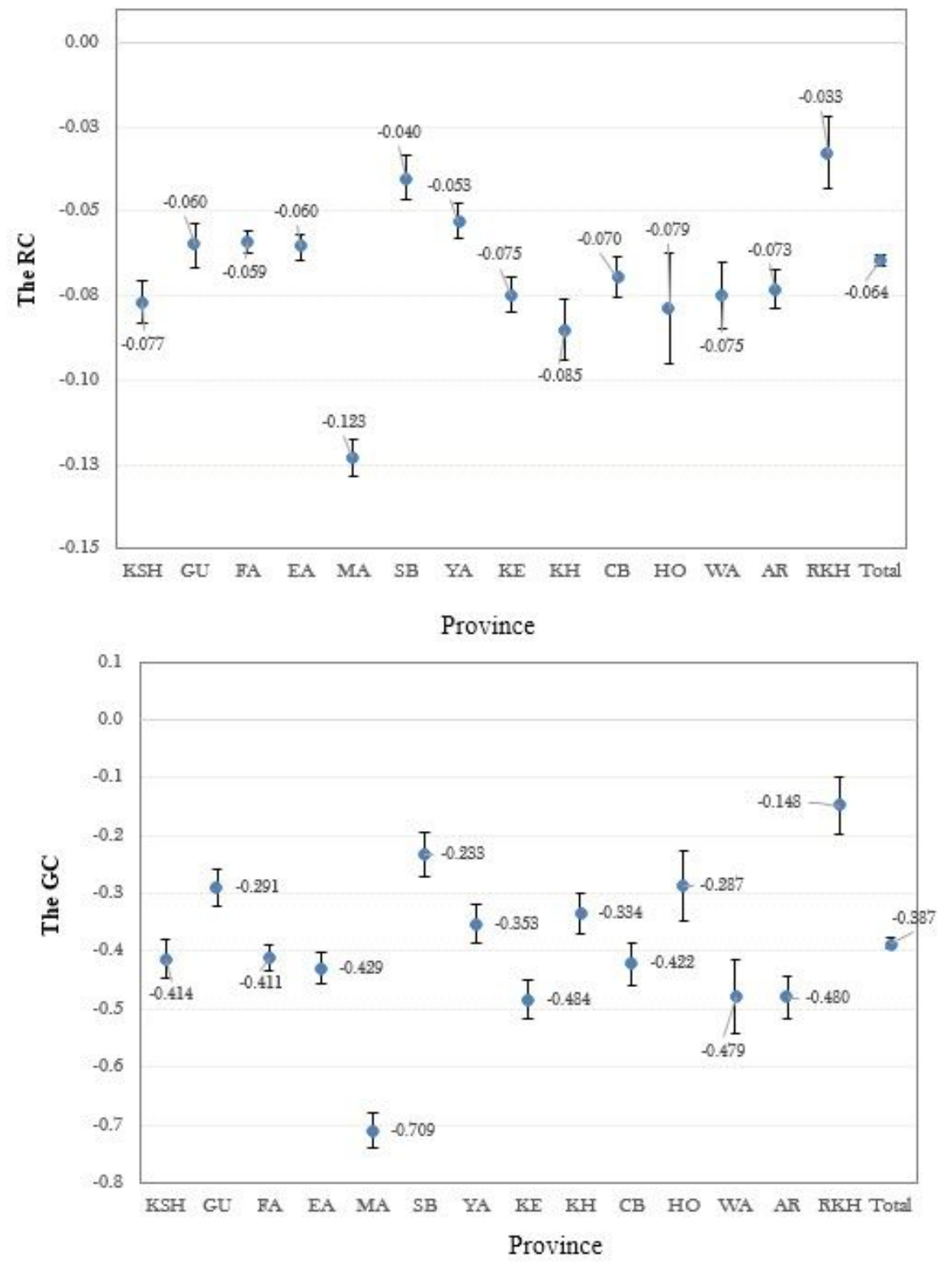

Figure 3

Socioeconomic-related inequalities in DMFT across 14 provinces in Iran. Note: with $95 \%$ confidence interval

\section{Supplementary Files}

This is a list of supplementary files associated with this preprint. Click to download.

- Formulas.jpg 